\title{
Barriers Facing Primary Health Care Physicians When Dealing with Emergency Cases in Jeddah, Saudi Arabia
}

\author{
Majed A. Aloufi ${ }^{1} \&$ Marwan A. Bakarman ${ }^{2}$ \\ ${ }^{1}$ General Directorate of Health, Ministery of Health, Jeddah, Saudia Arabia \\ ${ }^{2}$ Rabigh Faculty of Medicine, King Abdulaziz University, Jeddah, Saudia Arabia \\ Correspondence: Majed A. Aloufi, General Directorate of Health, Ministery of Health, Jeddah, Saudia Arabia. Tel: \\ 966-544-888-944. E-mail: majed_aloufi@hotmail.com
}

Received: October 20, 2015 Accepted: November 19, 2015 Online Published: December 17, 2015

doi:10.5539/gjhs.v8n8p192 URL: http://dx.doi.org/10.5539/gjhs.v8n8p192

\begin{abstract}
Objectives: To estimate the prevalence of emergency cases reporting to Primary Health Care centers (PHC), Jeddah, Saudi Arabia and to explore the barriers facing PHC physicians when dealing with such emergency cases.

Methods: A cross-sectional analytic study, where all physicians working in the PHC of the Ministry of Health $(\mathrm{MOH})$ in Jeddah; were invited to participate $(\mathrm{n}=247)$. The study period was from July 2013 till December 2013. Data were collected through two sources. 1- A self-administered questionnaire used to determine the physicians' perceived competence when dealing with emergency cases. 2- A structured observation sheet used to evaluate availability of equipment, drugs, ambulances and other supporting facilities required to deal with emergency cases.

Results: The response rate was $83.4 \%$. The physicians' age ranged between 25 and 60 years with a mean \pm SD of $34.4 \pm 7.5$ years. Majority of them $(83.5 \%)$ did not attend ATLS courses at all whereas $60.7 \%$ never attended ACLS courses. The majority (97.1\%) had however attended BLS courses. Physicians in the age group 36-45 years, non-Saudi, those who had SBFM, those who reported experience in working in emergency departments and physicians who reported more working years in PHCCs ( $>5$ years) had a significant higher score of perceived level of competence in performing emergency skill scale than others $(\mathrm{P}<0.05)$. The prevalence of emergency cases attending PHC in Jeddah (2013) was 5.2\%.
\end{abstract}

Conclusion: Emergency services at PHC in Jeddah are functioning reasonably well, but require fine tuning of services and an upgrade in their quality.

Keywords: emergency care, primary care physician, family medicine

\section{Introduction}

An emergency is "a sudden incident that necessitates urgent and appropriate management to treat its results and avoid its sequelae". It becomes a health emergency if it results in an unexpected risk to the health of people or the physical environment in which they live (Mahfouz et al., 2007).

Physicians working in the primary health care (PHC) setting may come across at least one emergency case per year. Seizures, asthma, shock and cardiac arrest are among the most common medical emergencies in PHC centers. Usually PHC centers are not fully prepared for these medical emergencies. Therefore, all PHC centers should have a written emergency protocol which guides them through the unexpected emergency case. PHC centers can effectively manage emergency cases by having the correct equipment, education and protocols (Toback, 2007; Shenoi et al., 2013)

Some may feel that physicians gain experience in managing acute emergencies during the secondary care portion of their training in hospitals, but several reasons exist why specific training for the primary care setting is essential. With the expansion of training in general physician for 12 months at the expense of secondary care training; physicians exposed to fewer opportunities to experience acute emergencies due to the lower prevalence in primary care as compaired to secondary care (Britton, 2010).

The context in which most physicians obtain and practice the skills for providing care for acute emergencies, e.g. 
Advanced Trauma Life Support (ATLS), Paediatric Advanced Life Support (PALS) etc., is in the heart of the hospital network; a network where a team of similarly trained and practiced professionals are present with resources, e.g. defibrillators, emergency medications etc., close to hand. Moreover, the teams get to practice with some regularity these skills on real cases (Britton, 2010).

In contrast to the above, in primary care, although the materials are usually available and maintained in case a situation should arise, these skills are rarely used. Moreover, the supportive practitioners (nurses, fellow clinicians and receptionists) although receiving yearly training; may wait years before they get to practice their skills on a real case. Indeed, the physicians being transferred from the relatively standardized and familiar context of the hospital or outpatient department to a new and much more variable primary care setting, therefore they will be disoriented and relatively isolated if confronted with a patient having a life threatening event. Finally, many physicians will never have taken the responsibility for directing the care or acting in lead clinician role during the emergency (Britton, 2010).

Data regarding emergency services at PHC level in Jeddah are scarce. Relevant data from health service providers, especially physicians, are very important to health care policy-makers for effective and optimal management of the current services.

The researcher adopted the following definition for emergency; it will include not only life-threatening situation but also will include emergency that will be managed totally or partially at PHC centers. Our objectives in this study were to estimate the prevalence of emergency cases reporting to PHC centres in Jeddah, Saudi Arabia and to explore the barriers facing PHC physicians when dealing with such emergency cases.

\section{Methodology}

\subsection{Research Desigin and Subjects}

This is a cross-sectional study where all the primary health care physicians working in the PHC centers of the Ministry Of Health (MOH) in Jeddah, Saudi Arabia during the study period. Forty PHC centres in Jeddah city where distributed in four geographical sectors. There are 218 general physicians and 67 family physicians working in those PHC centers. Total number of patients visiting PHC centers in 2013 was 1,340,553 patients.

\subsection{Sampling}

All the primary health care physicians who work in PHC centres, MOH in Jeddah city, at the period of the study constitute the target population. There total number was 285 physicains.

Thirty eight physicians were out of the work either internal or external. Thus, the total number of physicians invited to participate in the study was 247.

\subsection{Reseacrch Insturment}

The invited physicans were participated by completing a self-administered questionnaire structured by the researchers and validated by three consultants. The questionnaire contain the socio-demographic data, questions to identify level of their training, previous experience and emergency courses, questions to determine their perceived competence when dealing with emergency cases, frequency of emergency cases in the last 12 months and their satisfaction with emergency services provided at their PHC centers.

A structured observation sheet was also used to evaluate availability of equipments, drugs, ambulance and other supporting facilities which are needed to deal with emergency cases. This sheet was structured using the Saudi Ministry of Health Quality assurance manual, (Al-Mazrou \& Salem, 1993) the Saudi essential drug list at primary health care level (Al-Mazrou S, 2012) and the Saudi Ministry of Health Primary Health Care manual. (Al-Mazrou et al, 2003).

\subsection{Data Analysis}

Data entry and statistical analyses were done using statistical software package the SPSS version 20 . The study was from July 2013 till December 2013.

\section{Results}

Out of 247 PHC physicians recruited for the study, 206 responded by returning back completed questionnaires, a total response rate of $83.4 \%$.

Their age ranged between 25 and 60 years with a mean \pm SD of $34.4 \pm 7.5$ years. Almost two-thirds of them (64.5\%) aged between 25 and 35 years. Female physicians represent 59.2\%. Most were Saudi (71.8\%) and more than two-thirds (69.9\%) had obtained MBBS, while only 23 (11.2\%) physicians having the fellowship in Family Medicine. 
The vast majority of PHC physicians (97.1\%) had attended basic life support (BLS) courses, but (83.5\%) had not attended ATLS courses, with $60.7 \%$ never attending advanced cardiac life support (ACLS) courses. Out of the physicians who attended such courses, $46.1 \%$ attended BLS during the last year, whereas $6.8 \%$ and $5.3 \%$ of them attended ACLS and ATLS last year, respectively.

Most of PHC physicians (72.3\%) had previous experience of working in the emergency departments of hospitals.

Throughout the year 2013; there were 1,340,553 patients of varying ages visited the primary health care centers in Jeddah. Of these, 70,284 of these were labelled as emergency cases. Thus the prevalence of emergency cases attending PHC centers in Jeddah in 2013 was 5.2\%.

Most of the PHC physicians (70.4\%) have seen 3 or more cases of acute asthma in the last 12 months, whereas only $5.8 \%, 7.8 \%$ and $8.7 \%$ of the physicians have seen three or more cases of anaphylaxis, myocardial infarction and cardiac arrest in the last 12 months, respectively. More than a third (39.3\%) have seen three or more cases of renal colic and almost two thirds (63.1\%) did not see any case of myocardial infarction, convulsion (62.1\%), anaphylaxis $(68.9 \%)$ or acute vaginal bleeding $(65 \%)$. Most $(80.6 \%)$ did not see any case of cardiac arrest.

As shown in table 1, more than half of PHC physicians (50.5\%) will perform neublization and oxygen therapy in all cases, with $44.2 \%$ performing simple suturing in all cases. Just over a third of the physicians will attempt cardiac compression (38.8\%), bag \& mask resuscitation (37.9\%) and using intravenous (IV) fluid \& medications (36.4\%) in all cases. Only $9.7 \%$ and $16 \%$ of them will attempt intubation or defibrillation respectively, in all cases.

Table1. Perceived level of competence in performing emergency skills among primary health care physicians, $\mathrm{MOH}$, Jeddah

\begin{tabular}{lllll}
\hline $\begin{array}{l}\text { Factors associated with perceived } \\
\text { level of competence }\end{array}$ & $\begin{array}{l}\text { Would not know } \\
\text { where to start N } \\
(\%)\end{array}$ & $\begin{array}{l}\text { Will do if no one } \\
\text { else is available N } \\
(\%)\end{array}$ & $\begin{array}{l}\text { Will attempt in } \\
\text { most cases N } \\
(\%)\end{array}$ & $\begin{array}{l}\text { Will attempt in } \\
\text { all cases N } \\
(\%)\end{array}$ \\
\hline Cardiac compression & $9(4.4)$ & $44(21.4)$ & $73(35.4)$ & $80(38.8)$ \\
Mouth to mouth resuscitation & $21(10.2)$ & $74(35.9)$ & $53(25.7)$ & $58(28.2)$ \\
Bag \& mask resuscitation & $13(6.3)$ & $43(20.9)$ & $72(35.0)$ & $78(37.9)$ \\
Inserting IV cannula & $24(11.7)$ & $85(41.3)$ & $50(24.3)$ & $47(22.8)$ \\
Intubation & $71(34.5)$ & $77(37.4)$ & $38(18.4)$ & $20(9.7)$ \\
Defibrillation & $53(25.7)$ & $76(36.9)$ & $44(21.4)$ & $33(16.0)$ \\
Reading ECG* & $28(13.6)$ & $49(23.8)$ & $62(30.1)$ & $67(32.5)$ \\
Nebulisation \& oxygen therapy & $13(6.3)$ & $33(16.0)$ & $56(27.2)$ & $104(50.5)$ \\
Simple suturing & $25(12.1)$ & $43(20.9)$ & $47(22.8)$ & $94(44.2)$ \\
NGT insertion \# & $31(15.0)$ & $67(32.5)$ & $50(24.3)$ & $58(28.2)$ \\
Urinary catheter insertion & $27(13.1)$ & $74(35.9)$ & $42(20.4)$ & $63(30.6)$ \\
Administering IV fluid & $18(8.7)$ & $58(28.2)$ & $55(26.7)$ & $75(36.4)$ \\
\&medications** & & & & \\
\hline
\end{tabular}

\#NGT: Nasogastric tube; * ECG: Electrocardiogram; **IV: Intravenous.

Table 2 summarizes the factors associated with the perceived level of competence in performing emergency skills scale. Physicians in the age group 36-45 years reported the highest score of perceived level of competence in performing emergency scale skill (mean rank=126.30), followed by those aged over 45 years (mean rank=119.74) and finally those aged 35 years or less (mean rank=91.82). The difference was statistically significant, $\mathrm{p}=0.001$. None-Saudi physicians had a significant higher score of perceived level of competence in performing emergency skills scale compared to Saudis (mean rank was 120.94 versus 96.67, $\mathrm{P}=0.009$ ). Physicians who had Saudi Board of Family Medicine (SBFM) reported the highest score of perceived level of competence in performing emergency skills scale (mean score=152.76) whereas those who had Medical bachelors and bachelors of surgery (MBBS) reported the lowest score (mean rank=92.98). The difference was statistically significant, $\mathrm{P}<0.001$. Physicians who reported experience in working in emergency departments had significant higher score of perceived level of competence in performing emergency skills scale (mean score was 111.50 versus $82.59, \mathrm{P}=0.002$ ). Physicians who reported more years in $\mathrm{PHC}$ practice ( $>5$ years) had significant higher score of perceived level of competence in performing emergency skills scale than those with lower years 
in PHC practice (<one year) (mean score was 121.90 versus $85.35, \mathrm{P}=0.001$ ). Physician`s gender and attending courses of BLS, ATLS and ACLS were not significantly associated with the score of perceived level of competence in performing emergency skills scale.

Table 2. Factors associated with perceived level of competence in performing emergency scale skill among PHC physicians

\begin{tabular}{|c|c|c|c|c|}
\hline \multirow[t]{2}{*}{ Physician factors } & \multicolumn{3}{|c|}{$\begin{array}{l}\text { Score of level of competence in performing emergency scale } \\
\text { skill(12-48) }\end{array}$} & \multirow[t]{2}{*}{ P-value } \\
\hline & Median & IQR & Mean rank & \\
\hline \multicolumn{5}{|l|}{ Age in years: } \\
\hline $25-35$ & 31 & $26-73$ & 91.82 & \\
\hline $36-45$ & 37 & $32-42$ & 126.30 & \\
\hline$>45$ & 37 & $27-42$ & 119.74 & $0.001 * *$ \\
\hline \multicolumn{5}{|l|}{ Gender: } \\
\hline Male & 33.5 & $28-38$ & 104.25 & \\
\hline Female & 33 & $26-39$ & 102.98 & $0.881 *$ \\
\hline \multicolumn{5}{|l|}{ Nationality: } \\
\hline Saudi & 32 & $27-37$ & 96.67 & \\
\hline Non-Saudi & 37 & $28-42$ & 120.94 & $0.009 *$ \\
\hline \multicolumn{5}{|l|}{ Qualification: } \\
\hline MBBS & 31 & $26-37$ & 92.98 & \\
\hline $\mathrm{ABFM}^{\phi}$ & 35 & $33.5-40.5$ & 131.17 & \\
\hline SBFM $^{\phi \phi}$ & 39 & $36-44.5$ & 152.76 & \\
\hline FM Diploma & 35.5 & $32-40.75$ & 129.04 & \\
\hline Others & 37 & $23.5-41$ & 109.68 & $<0.001 * *$ \\
\hline \multicolumn{5}{|l|}{ BLS: } \\
\hline$<1$ year & 34 & $28-39$ & 107.35 & \\
\hline $1-2$ years & 34 & $28-39$ & 109.14 & \\
\hline$>2$ years & 29 & $23-38$ & 81.02 & \\
\hline Not at all & 25.5 & $20.75-39.75$ & 75.0 & $0.092 * *$ \\
\hline \multicolumn{5}{|l|}{ ACLS: } \\
\hline$<1$ year & 38 & $33.75-41$ & 136.07 & \\
\hline $1-2$ years & 34 & $26.5-37.5$ & 100.36 & \\
\hline$>2$ years & 33 & $28-40.25$ & 107.67 & \\
\hline Not at all & 33 & $26-38$ & 98.84 & $0.155^{* *}$ \\
\hline \multicolumn{5}{|l|}{ ATLS: } \\
\hline$<1$ year & 35 & $27-38$ & 102.09 & \\
\hline $1-2$ years & 35.5 & $32-36$ & 113.0 & \\
\hline$>2$ years & 36 & $29-39$ & 117.58 & \\
\hline Not at all & 33 & $27-38.75$ & 101.81 & $0.727 * *$ \\
\hline \multicolumn{5}{|l|}{ Experience: } \\
\hline Yes & 35 & $28-40$ & 111.50 & \\
\hline No & 30 & $24-37$ & 82.59 & $0.002 *$ \\
\hline \multicolumn{5}{|c|}{$\begin{array}{l}\text { Years of working in } \\
\text { PHC: }\end{array}$} \\
\hline$<1$ & 31 & $26.25-35.75$ & 85.35 & \\
\hline $1-5$ & 32 & $26.5-37.50$ & 94.96 & \\
\hline$>5$ & 36 & $29-42.5$ & 121.90 & $0.001 * *$ \\
\hline
\end{tabular}


Table 3 shows us the highest rate of satisfaction with all emergency services provided at PHC centers (facilities, equipment, trained personnel and medications) were reported in dealing with acute asthma (47.1\%), followed by renal colic $(32 \%)$ and hypoglycemia $(24.3 \%)$, whereas the lowest rates were reported in dealing with cases of acute Gastrointestinal tract (GIT) bleeding (4.4\%), myocardial infarction (4.9\%), cardiac arrest $(7.3 \%)$, acute vaginal bleeding $(7.8 \%)$, angina pectoris $(8.3 \%)$ and convulsions $(8.7 \%)$. On the other hand, the highest rate of dissatisfaction with all emergency services provided at PHC centers were reported in dealing with cardiac arrest (51.9\%), acute GIT bleeding (40.8\%), acute vaginal bleeding (39.3\%) and myocardial infarction (38.3\%). Dissatisfaction with trained personnel (physicians and nurses), the highest rates reported in dealing with cases of hypoglycemia (26.7\%), severe dehydration (25.7\%), myocardial infarction (23.8\%) and diabetic ketoacidosis (23.3\%). Dissatisfaction with availability of medications, the highest rates were reported in cases of hypoglycemia (23.3\%), renal colic (19.9\%), diabetic ketoacidosis $(19.9 \%)$ and angina pectoris $(18.9 \%)$. Concerning the dissatisfaction with facilities and equipment, the highest rates were reported in cases of acute GIT bleeding (20.4\%), convulsions (19.4\%), anaphylaxis (18.9\%) and acute vaginal bleeding (18.4\%).

Table 3. Satisfaction of the PHC physicians with the emergency services provided at PHC centre

\begin{tabular}{llllll}
\hline Emergency & \multicolumn{5}{l}{ Satisfaction with the emergency services provided at PHC centre } \\
\cline { 2 - 6 } Conditions & $1 \mathrm{~N}(\%)$ & $2 \mathrm{~N}(\%)$ & $3 \mathrm{~N}(\%)$ & $4 \mathrm{~N}(\%)$ & $5 \mathrm{~N}(\%)$ \\
\hline Acute asthma & $97(47.1)$ & $32(15.5)$ & $36(17.5)$ & $16(7.8)$ & $25(12.1)$ \\
Myocardial infarction & $10(4.9)$ & $49(23.8)$ & $32(15.5)$ & $36(17.5)$ & $79(38.3)$ \\
Angina pectoris & $17(8.3)$ & $47(22.8)$ & $39(18.9)$ & $34(16.5)$ & $69(33.5)$ \\
Cardiac arrest & $15(7.3)$ & $39(18.9)$ & $21(10.2)$ & $24(11.7)$ & $107(51.9)$ \\
Severe dehydration & $41(19.9)$ & $53(25.7)$ & $33(16.0)$ & $35(17.0)$ & $44(21.4)$ \\
Renal colic & $66(32.0)$ & $39(18.9)$ & $41(19.9)$ & $32(15.5)$ & $28(13.6)$ \\
Acute GIT bleeding & $9(4.4)$ & $43(20.9)$ & $28(13.6)$ & $42(20.4)$ & $84(40.8)$ \\
Hypoglycemia & $50(24.3)$ & $55(26.7)$ & $48(23.3)$ & $26(12.6)$ & $27(13.1)$ \\
Diabetic ketoacidosis & $22(10.7)$ & $48(23.3)$ & $41(19.9)$ & $35(17.0)$ & $60(29.1)$ \\
Convulsions & $18(8.7)$ & $42(20.4)$ & $34(16.5)$ & $40(19.4)$ & $72(35.0)$ \\
Anaphylaxis & $23(11.2)$ & $47(22.8)$ & $35(17.0)$ & $39(18.9)$ & $62(30.1)$ \\
Acute vaginal bleeding & $16(7.8)$ & $40(19.4)$ & $31(15.0)$ & $38(18.4)$ & $81(39.3)$ \\
\hline
\end{tabular}

$1=\mathrm{I}$ am satisfied with the facilities, equipment, trained health care personnel and medications available to deal with such cases.

$2=\mathrm{I}$ am satisfied with the facilities, equipment and medications but we need more training for health care personnel (physicians and nurses) when dealing with such cases.

$3=\mathrm{I}$ am satisfied with the facilities, equipment and trained health care personnel but medications are deficient when dealing with such cases.

4=I am satisfied with the medications and trained personnel but facilities and equipment are deficient when dealing with such cases.

$5=\mathrm{I}$ am overall not satisfied about the services provided at our PHC centre when dealing with such cases.

Table 4. Availability of equipment, medication and supporting facilities needed for emergency care at primary health care centers in Jeddah $(\mathrm{N}=42)$

\begin{tabular}{llllll}
\hline Equipment needed & & \multicolumn{2}{l}{ Medications and intravenous fluid needed } & \multicolumn{2}{l}{ Supporting facilities } \\
\hline Items & $\mathbf{N ~ ( \% )}$ & Items & $\mathbf{N ~ ( \% )}$ & Items & $\mathbf{N}(\%)$ \\
\hline Side lamp with stand & $31(73.8)$ & Calcium chloride injection & $16(38.1)$ & X-ray & $19(45.2)$ \\
Dressing drum & $35(83.3)$ & Antihistaminic injection & $37(88.1)$ & $\begin{array}{l}\text { Laboratory } \\
\text { 41(97.6) }\end{array}$ \\
Dressing trays & $40(95.2)$ & Hydrocortisone injection & E1(97.6) & $\begin{array}{l}\text { Equipped } \\
\text { ambulance } \\
\text { cars }\end{array}$ \\
\hline
\end{tabular}




\begin{tabular}{|c|c|c|c|c|c|}
\hline \multicolumn{2}{|l|}{ Equipment needed } & \multicolumn{2}{|c|}{ Medications and intravenous fluid needed } & \multicolumn{2}{|c|}{ Supporting facilities } \\
\hline Items & $\mathbf{N}(\%)$ & Items & $\mathbf{N}(\%)$ & Items & $\mathbf{N}(\%)$ \\
\hline Dressing table & $38(90.5)$ & Dextrose $5 \%, 10 \%, 50 \%$ & $42(100)$ & & \\
\hline Urinary catheter & $15(35.7)$ & Normal saline & $42(100)$ & & \\
\hline Forceps & 41(97.6) & Ringer lactate & $42(100)$ & & \\
\hline Scissors & $40(95.2)$ & Activated charcoal powder & $3(7.14)$ & & \\
\hline Suture materials & $35(83.3)$ & Metoclopramide & $41(97.6)$ & & \\
\hline Needle holder & $40(95.2)$ & Adrenaline injection & $41(97.6)$ & & \\
\hline Suction apparatus & $24(57.1)$ & Ventolin for neublization & $42(100)$ & & \\
\hline Blades & $40(95.2)$ & Anti-tetanic serum & $0(0)$ & & \\
\hline IV stand & $40(95.2)$ & Tetanus toxoid & $40(95.2)$ & & \\
\hline Nasogastric tubes & $16(38.1)$ & Diazepam & $38(90.5)$ & & \\
\hline Cannulas & $42(100)$ & Furosemide & $42(100)$ & & \\
\hline Cervical collars & $5(11.9)$ & Hyoscine & $42(100)$ & & \\
\hline Oxygen mask & $42(100)$ & & & & \\
\hline Airways equipment & $19(45.2)$ & & & & \\
\hline Oxygen cylinder with Standard fitting & $42(100)$ & & & & \\
\hline Ambu bag & $27(64.3)$ & & & & \\
\hline Nebulizer & $40(95.2)$ & & & & \\
\hline
\end{tabular}

Table 4 describes the frequencies and percentages of equipments, medications and supporting facilities available for emergency care in 42 PHCCs. Oxygen cylinders with standard fitting, oxygen mask, cannulas were available in all PHCCs. On the other hand, cervical collars were available in only 5 PHCCs (5.9\%), urinary catheters in 15 PHCCs (35.7\%) and nasogastric tube in 16 PHCCs (38.1\%). Medications and intravenous fluids, Dextrose 5\%, $10 \%, 50 \%$, Ringer lactate, normal saline, Ventolin for neublization, Diazepam , Furosemide and Hyoscine were available in all PHCCs whereas Anti-tetanic serum was not available in any PHCC. Activated charcoal powder was available in only 3 PHCCs (7.14\%). Supporting facilities, laboratory was available in 41 PHCCs (97.6\%) whereas x-ray and equipped ambulance cars were available in $45.2 \%$ and $28.6 \%$ of PHCCs, respectively.

\section{Discussion}

Several studies have shown that emergency situations are to be expected in an active family practice/primary health care office (Klig, 2007; Yorganci \& Yaman, 2008). An emergency is "a sudden incident that necessitates urgent and appropriate management to treat its results and avoid its sequelae" (Mahfouz et al., 2007).

In our study, the prevalence of emergency cases among patients attending PHCCs in Jeddah throughout 2013 was 5.2\%. Medical emergency cases in PHC in Norway found to be less than 3\% (Zakariassen, Hansen, \& Hunskaar, 2007). In Netherlands the emergency cases were only $4.6 \%$ for the general practitioner (Charante et al., 2007).

This study quantifies the average number and types of emergencies seen in PHC centers in Jeddah, allowing the medical authorities to grasp the importance of improving preparedness of these centers for emergencies. In our survey, more than $70 \%$ of the PHC physicians have seen more than three cases of acute bronchial asthma in the last 12 months; in addition frequent cases of renal colic and hypoglycemia were reported. A study done in rural Australia found that the General Practictionars saw a median of eight emergencies per year, and that 95 percent had seen at least one emergency in the preceding 12 months (Johnston et al, 2001). Other study found that the average family practice office has 3.8 childhood emergencies each year (Mansfield et al., 2001). Another study found that $62 \%$ of family medicine and child care offices saw one or more children who required hospitalization or urgent treatment each week (Ablah et al., 2008).

Two thirds of PHC physicians in our study had only attained Bachelor degree level, where the physicians with higher qualification presented an increased score of perceived level of competence in performing emergency skills. Previous studies in Saudi Arabia showed that the majority of PHC physicians would like to acquire more 
knowledge and skills related to emergency medicine (Almalki, Fitzgerald, \& Clark, 2011).

\section{Concluision}

The present study showed that emergency services at PHC level in Jeddah, Saudi Arabia are functioning reasonably well in some terms. However, the services need to be fine-tuned, and defects revealed by the present study should be taken into consideration hand-in-hand with available resources in order to upgrade the quality of the emergency services provided at PHC centers in Jeddah. Level of training and emergency courses of PHC physicians is suboptimal particularly in ATLS and ACLS courses.

Older, non-Saudi, more qualified, more experienced physicians and those having more years in PHC showed higher perceived level of competence in performing emergency skill.

\section{Conflict of Interest}

The authors declare that there is no conflict of interests regarding the publication of this paper.

\section{References}

Ablah, E., Tinius, A. M., Hom, L., Williams, C., \& Gebbie, K. M. (2008). Community health centers and emergency preparedness: An assessment of competencies and training needs. J Community Health, 33(4), 241-247. http://dx.doi.org/10.1007/s10900-008-9093-9

Almalki, M., Fitzgerald, G., \& Clark, M. (2011). Health care system in Saudi Arabia: An overview. East Mediterr Health J., 17(10), 784-793.

Al-Mazrou, S. (2012). Saudi essential drug list at primary health care level. Riyadh, Saudi Arabia, Ministry of Health (first revised ed.).

Al-Mazrou, Y., Farag, M. (1993). Manual of quality assurance in primary health care (1st ed.). Riyadh, Saudi Arabia, General Directorate of Health Centres, Ministry of Health.

Al-Mazrou, Y., Salem, A. (2003). Manual of primary health care. Riyadh, Saudi Arabia, General Directorate of Health Centres, Ministry of Health.

Britton, E. (2010). Managing emergency in primary care. London Deanery.

Johnston, C. L., Coulthard, M. G., Schluter, P. J., \& Dick, M. L. (2001). Medical emergencies in general practice in south-east Queensland: Prevalence and practice preparedness. Med J, 175, 99-103.

Klig, J. E., \& O’Malley, P. J. (2007). Pediatric office emergencies. Curr Opin Pediatr, 19(5), 591-596. http://dx.doi.org/10.1097/MOP.0b013e3282efd4cc

Mahfouz, A. A., Abdelmoneim, I., Khan, M. Y., Daffalla, A. A., Diab, M. M., El-Gamal, M. N., \& Al-Sharif, A. (2007). Primary health care emergency services in Abha district of southwestern Saudi Arabia. East Mediterr Health J., 13(1), 103-112.

Mansfield, C. J., Price, J., Frush, K. S., \& Dallara, J. (2001). Pediatric emergencies in the office: Are family physicians as prepared as pediatricians? J Fam Pract, 50, 757761.

Moll van Charante, E. P., van Steenwijk-Opdam, P. C., \& Bindels, P. J. (2007). Out-ofhours demand for GP care and emergency services: Patients' choices and referrals by general practitioners and ambulance services. BMC FAM Pract, 8, 46. http://dx.doi.org/10.1186/1471-2296-8-46

Shenoi, R., Li, J., Jones, J., \& Pereira, F. (2013). An education program on office medical emergency preparedness for primary care pediatricians. Teach Learn Med, 25(3), 216-224. http://dx.doi.org/10.1080/ 10401334.2013.797354

Toback, S. L. (2007). Medical emergency preparedness in office practice. Am Fam Physician, 1, 75(11), 1679-1684.

Yorganci, M., \& Yaman, H. (2008). Preparedness of primary healthcare centers for critical emergency situations in southwest Turkey. Prehosp Disaster Med, 23(4), 342-345.

Zakariassen, E., Hansen, E. H., \& Hunskaar, S. (2009). Incidence of emergency contacts (red responses) to Norwegian emergency primary healthcare services in 2007-a prospective observational study. Scandinavian Journal of Trauma, Resuscitation and Emergency Medicine, 17, 30. http://dx.doi.org/10.1186/1757 $-7241-17-30$ 


\section{Copyrights}

Copyright for this article is retained by the author(s), with first publication rights granted to the journal.

This is an open-access article distributed under the terms and conditions of the Creative Commons Attribution license (http://creativecommons.org/licenses/by/3.0/). 